Article

\title{
Three-Dimensional Porous Nitrogen-Doped NiO Nanostructures as Highly Sensitive $\mathrm{NO}_{2}$ Sensors
}

\author{
Van Hoang Luan ${ }^{1}$, Huynh Ngoc Tien ${ }^{2} \mathbb{B}^{D}$, Seung Hyun Hur ${ }^{3}$, Jong Hun Han ${ }^{4}$ and Wonoh Lee ${ }^{1, *}$ \\ (iD) \\ 1 School of Mechanical Engineering, Chonnam National University, 77 Yongbong-ro, Buk-gu, Gwangju 61186, \\ Korea; vhluan1986@gmail.com \\ 2 Department of Chemical Engineering, University of South Carolina, 301 Main Street, Columbia, SC 29208, \\ USA; huynhngoctien@gmail.com \\ 3 School of Chemical Engineering and Bioengineering, University of Ulsan, 93 Daehak-ro, Nam-gu, \\ Ulsan 44610, Korea; shhur@mail.ulsan.ac.kr \\ 4 School of Chemical Engineering, Chonnam National University, 77 Yongbong-ro, Buk-gu, Gwangju 61186, \\ Korea; jhhan@jnu.ac.kr \\ * Correspondence: wonohlee@jnu.ac.kr; Tel.: +82-62-530-1682
}

Received: 11 September 2017; Accepted: 8 October 2017; Published: 11 October 2017

\begin{abstract}
Nickel oxide has been widely used in chemical sensing applications, because it has an excellent p-type semiconducting property with high chemical stability. Here, we present a novel technique of fabricating three-dimensional porous nitrogen-doped nickel oxide nanosheets as a highly sensitive $\mathrm{NO}_{2}$ sensor. The elaborate nanostructure was prepared by a simple and effective hydrothermal synthesis method. Subsequently, nitrogen doping was achieved by thermal treatment with ammonia gas. When the p-type dopant, i.e., nitrogen atoms, was introduced in the three-dimensional nanostructures, the nickel-oxide-nanosheet-based sensor showed considerable $\mathrm{NO}_{2}$ sensing ability with two-fold higher responsivity and sensitivity compared to non-doped nickel-oxide-based sensors.
\end{abstract}

Keywords: sensor; porous nanostructure; nickel oxide; nitrogen doping; $\mathrm{NO}_{2}$ gas sensor

\section{Introduction}

Nitrogen dioxide $\left(\mathrm{NO}_{2}\right)$ is an important air pollutant because it contributes to the formation of photochemical smog, which has significantly harmful impacts on human health. Public awareness about the dangers of $\mathrm{NO}_{2}$ has increased the demand for detecting this hazardous gas with high precision sensors composed of highly sensitive materials. Therefore, numerous approaches have been suggested to detect $\mathrm{NO}_{2}$ at the ppm level [1-3]. Among the various types of gas sensors, semiconducting metal oxide gas sensors have attracted much attention because of their low cost, ease of production, simplicity of use, and ability to detect numerous gases, e.g., those using tungsten trioxide, titanium dioxide, vanadium oxide, tin dioxide, and nickel oxide $(\mathrm{NiO})$ [4-6].

$\mathrm{NiO}$, a well-known stable p-type semiconducting metal oxide, has a high melting point $\left(1960^{\circ} \mathrm{C}\right)$ and excellent chemical stability. Therefore, it has been extensively employed as electrodes in lithium ion batteries and supercapacitors, as electro-catalysts in combustion gas sensing, and in electrochromic devices [7-9]. Furthermore, a novel nanostructure with a high specific surface area is essential for enhanced performance of the NiO-based devices, which can be achieved by reactive sputtering, sol-gel methods, and hydrothermal treatments [10-14]. Therefore, highly porous $\mathrm{NiO}$ nanostructures can be used to fabricate highly sensitive gas sensors, especially for $\mathrm{NO}_{2}$ detection, because the p-type semiconducting $\mathrm{NiO}$ can effectively donate electrons to the $\mathrm{NO}_{2}$ molecules. 
Previous studies have reported that nitrogen $(\mathrm{N})$ is a good dopant in many metal oxides because $\mathrm{N}$ and oxygen have similar ionic radii [15-17]. N-doping in titanium dioxide effectively improved its electro-catalytic performance in the carbon monoxide gas reaction [18], and promoted $\mathrm{NO}_{2}$ adsorption as proven theoretically via density functional theory calculation [19]. Furthermore, the intrinsic electrical resistance and signal noise level of metal oxides could be overcome via N-doping [20-22].

Herein, we present three-dimensional porous $\mathrm{N}$-doped $\mathrm{NiO}$ nanosheets (NSs) for highly sensitive $\mathrm{NO}_{2}$ sensing applications. The elaborate $\mathrm{NiO}$ nanostructure was prepared by a simple and effective solution-based hydrothermal method [23,24]. Subsequently, N-doping was achieved by thermal treatment with ammonia gas. Figure 1 shows the $\mathrm{N}$-doped $\mathrm{NiO}$ nanostructure used in $\mathrm{NO}_{2}$ sensing. The $\mathrm{N}$-doped $\mathrm{NiO}$ nanostructure is hydrothermally grown on a silicon/silicon dioxide $\left(\mathrm{Si} / \mathrm{SiO}_{2}\right)$ wafer and gold $(\mathrm{Au})$ electrodes are deposited to measure the electrical signals during $\mathrm{NO}_{2}$ exposure. Owing to the $\mathrm{N}$-doping effect with hierarchical nanostructure, the resistance change in the gas sensor can be greatly amplified. The result shows that the $\mathrm{N}$-doped NiO-based gas sensor, compared to a non-doped sensor, exhibits a two-fold higher responsivity and sensitivity toward $\mathrm{NO}_{2}$ gas detection and is thus a candidate for highly sensitive $\mathrm{NO}_{2}$ sensors.

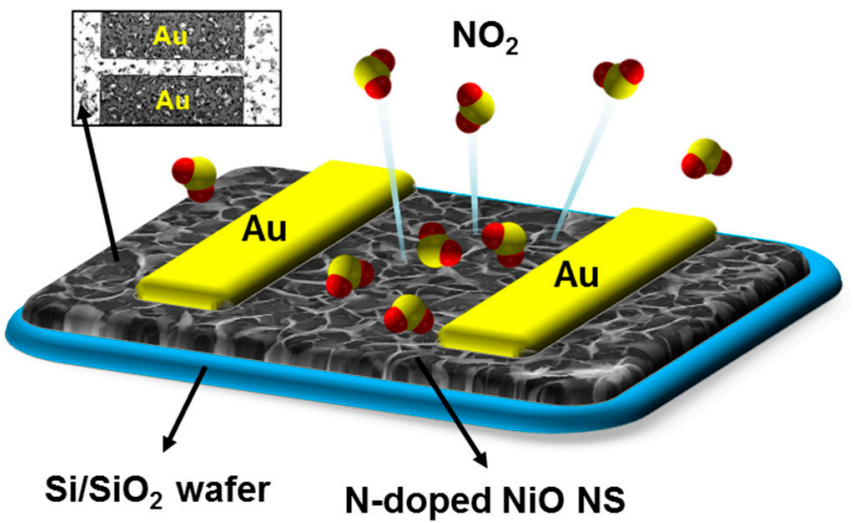

Figure 1. A schematic illustration and a top-view image of a three-dimensional porous $\mathrm{N}$-doped $\mathrm{NO}_{2}$ gas sensor based on $\mathrm{NiO}$ nanosheets (NSs).

\section{Materials and Methods}

\subsection{Synthesis of the $\mathrm{NiO}$ Nanostructure}

The three-dimensional porous $\mathrm{NiO}$ nanostructure was synthesized via sequential seeding and growth [23,24], and all reagents were purchased from Sigma-Aldrich, Korea. Nickel acetate tetrahydrate $(0.2 \mathrm{M})$ was dissolved in a mixture of 2-methoxyethanol $(6 \mathrm{~mL})$ and diethanolamine $(0.25 \mathrm{~mL})$ to obtain an $\mathrm{NiO}$ seed solution. After the seed solution was stirred for $2 \mathrm{~h}$ at room temperature, it was spin-coated at $4000 \mathrm{rpm}$ for $30 \mathrm{~s}$ on an $\mathrm{Si} / \mathrm{SiO}_{2}$ wafer and dried on a hot-plate at $250{ }^{\circ} \mathrm{C}$ for $15 \mathrm{~s}$. After the spin-coating process was repeated three times, the sample was annealed at $400{ }^{\circ} \mathrm{C}$ for $2 \mathrm{~h}$ in a vacuum chamber. Note that a higher rotating speed and a longer spinning time may produce an irregular and/or thin coating layer owing to excessive centrifugal force. Here, we found that the above condition was optimal for constructing uniform and stable seed layer with strong adhesion on the substrate [23]. At the next stage, an $\mathrm{NiO}$ growth solution was prepared by dissolving nickel nitrate hexahydrate $(5.8 \mathrm{~g})$ and hexamethylenetetramine $(4.8 \mathrm{~g})$ in distilled (DI) water $(100 \mathrm{~mL})$. The NiO-seed-coated wafer was dipped in the growth solution at $90^{\circ} \mathrm{C}$ for $2 \mathrm{~h}$, rinsed with DI water, and annealed at $350{ }^{\circ} \mathrm{C}$ for $1 \mathrm{~h}$. The annealing process was performed in a gas chamber filled with argon $(1 \mathrm{~atm})$ and ammonia $(50 \mathrm{sccm})$ for $\mathrm{N}$-doping. Au electrodes were then deposited on the surface of the $\mathrm{N}$-doped $\mathrm{NiO}$ nanostructure via thermal evaporation in vacuum. 


\subsection{Chracterization of the $\mathrm{N}$-Doped $\mathrm{NiO}$ Nanostructure}

The porous morphology of the synthesized $\mathrm{NiO}$ nanostructure was investigated by scanning electron microscopy (SEM, JEOL JSM-6500FE, Tokyo, Japan). X-ray diffraction (XRD) measurements were carried out to identify the crystal structure of $\mathrm{NiO}$ using a high-resolution $\mathrm{X}$-ray diffractometer (Rigaku, D/MAXZ-2500V, Tokyo, Japan). The Brunauer-Emmett-Teller (BET) specific surface areas of the powders were determined by nitrogen adsorption in a Micromeritics ASAP 2020 (Norcross, GA, USA) nitrogen adsorption apparatus. Successful N-doping was examined by X-ray photoelectron spectroscopy (XPS) using a Thermo Fisher Scientific ESCALAB 250Xi (Waltham, MA, USA). The gas sensing properties were evaluated by measuring the resistance change with a Hewlett-Packard 4155A semiconductor parametric analyzer in a MST-5000 gas chamber (MS-Tech, Hwasung, Gyeonggi-do, Korea). In order to measure the electrical resistance, an Au layer consisting of electrodes was deposited on the surface of the $\mathrm{N}$-doped $\mathrm{NiO}$ nanostructure using a thermal evaporator with a patterned mask. The thickness of the Au coat was $50 \mathrm{~nm}$ from the top surface of the NiO nanostructure and had a $10 \mu \mathrm{m}$ spacing. The concentration of $\mathrm{NO}_{2}$ was carefully controlled using a mass flow controller (GMC 1200, ATOVAC, Yongin, Gyeonggi-do, Korea).

\section{Results and Discussion}

\subsection{Morphology of the N-Doped NiO-NS Nanostructure}

The three-dimensional porous nanostructure of N-doped NiO NSs (Figure 2) shows that the thickness and height of the grown NSs were 20-30 nm and 1-3 $\mu \mathrm{m}$, respectively, in close agreement with the previously reported values $[23,24]$. The porous nanostructure hierarchically grown on the wafer had a high surface area of $\sim 205 \mathrm{~m}^{2} / \mathrm{g}$, suggesting an enhanced gas adsorption ability, and can thus be applied in high-performance $\mathrm{NO}_{2}$ sensors. Energy-dispersive $\mathrm{X}$-ray spectrometry (EDS) mapping analysis of the elements is shown in Figure 3. Uniformly dispersed green and red dots on the $\mathrm{N}$-doped $\mathrm{NiO} \mathrm{NSs}$ indicate the successful growth of $\mathrm{NiO}$ nanosheets. Note that the $\mathrm{N}$-mapping in the EDS spectrum was somewhat unclear owing to the strong intensity of $\mathrm{Ni}$ and $\mathrm{O}$. The identification of the $\mathrm{N}$ element was examined via XPS analysis.
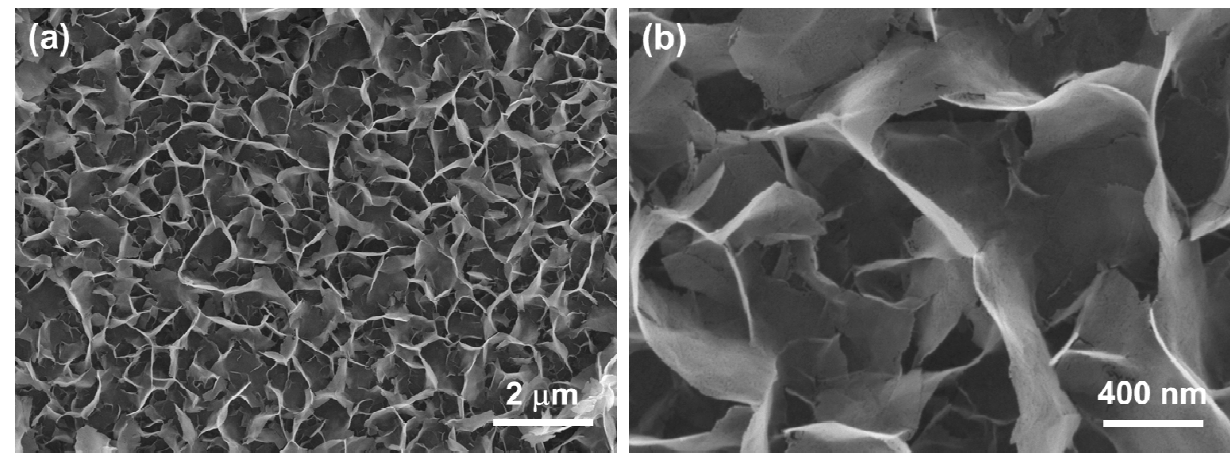

Figure 2. SEM images of (a) the three-dimensional nanostructure of N-doped NiO NSs and (b) its magnified image.
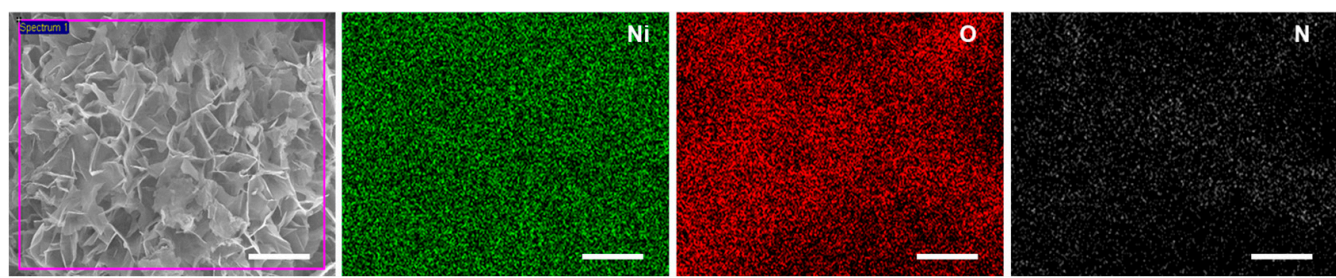

Figure 3. EDS mapping images of N-doped NiO NSs (scale bar $=4 \mu \mathrm{m}$ ). 


\subsection{Crystallinity of the N-Doped NiO NS}

Figure 4 shows three distinguishable diffraction peaks at $37.2^{\circ}, 43.5^{\circ}$, and $62.3^{\circ}$, corresponding to the (111), (200), and (220) $\mathrm{NiO}$ planes, respectively, indicating high crystallinity for both $\mathrm{N}$-doped and non-doped NiO NSs [7,20,24]. All reflections in the XRD pattern can be indexed to face-centered-cubic-phase NiO (JCPDS card \#47-1049) [25]. Since both peak positions and intensities are almost the same for $\mathrm{N}$-doped and non-doped NiO NSs, it can be concluded that doping by nitrogen atoms has no influence on the intrinsic crystal structure of $\mathrm{NiO}$. The high peak intensity indicates that the prepared NiO NSs are highly crystalline. Moreover, for the N-doped NiO NSs, crystallinity higher than that of the non-doped NiO NSs can also be verified by calculating the grain sizes from crystallographic parameters. The Scherrer's formula was used to calculate the crystallite size $D$ of the manufactured NiO NSs using Equation (1) [26,27]:

$$
D=\frac{0.9 \lambda}{\beta \cos \theta}
$$

where $\lambda$ is the wavelength of the X-ray source (1.54 $\AA$ ), $\beta$ is the full width at half maximum of high-intensity peaks, and $\theta$ is the Bragg's angle $[28,29]$. The obtained $\beta$ and $D$ values are listed in Table 1, where the N-doped NiO NSs have relatively larger grain sizes than those of the non-doped NSs. Therefore, it can be estimated that N-doping can increase the crystallinity of NiO NSs. The Scherrer equation is generally applicable for spherical particles; it has limitations because many factors may contribute to peak broadening in the XRD patterns. For example, the deposition and growth of materials on substrates may produce crystallographic strain due to residual stress. Herein, assuming the same circumstance for N-doped and non-doped NiO NSs, we investigated only their relative crystallinities.

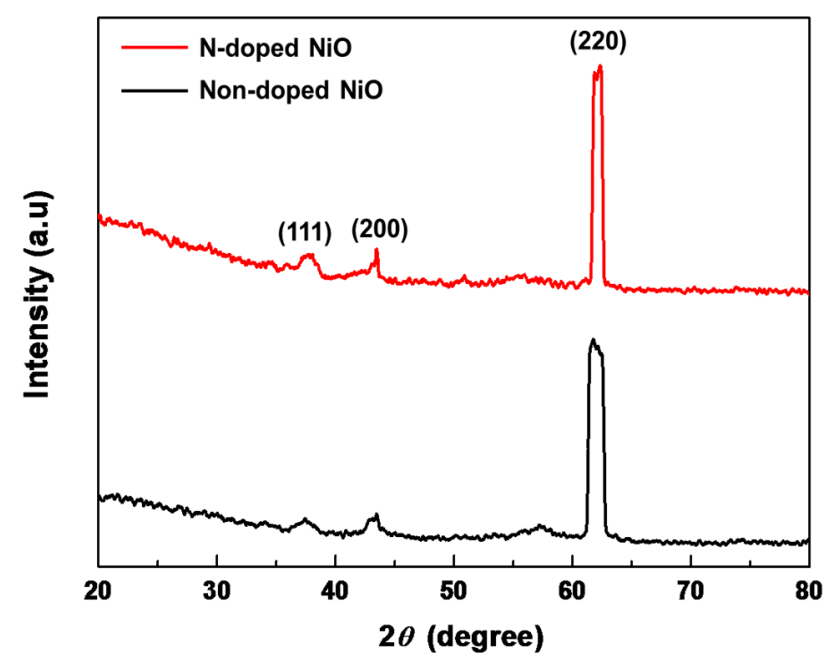

Figure 4. XRD results of N-doped and non-doped NiO NSs.

Table 1. Structural crystal parameters of N-doped and non-doped NiO NSs.

\begin{tabular}{ccc}
\hline Sample & $\boldsymbol{\beta}$ (Deg) & $\boldsymbol{D}$ (nm) \\
\hline N-doped NiO & $0.65 \pm 0.02$ & $26.3 \pm 0.8$ \\
Non-doped NiO & $1.42 \pm 0.05$ & $12.0 \pm 0.5$ \\
\hline
\end{tabular}

\subsection{Chemical Characterization of the N-Doped NiO NSs}

The chemical structure of $\mathrm{NiO}$ was examined, and $\mathrm{N}$-doping was confirmed using XPS analyses. Both N-doped and non-doped NiO NSs showed the peaks of O 1s and Ni 2p (Figure 5), with two 
split peaks of 2p1/2 (872.1 eV) and 2p3/2 (853.2 eV), and a satellite peak of 2p3/2 (860.1 eV) [30,31]. A peak of $\mathrm{N} 1 \mathrm{~s}$ was only observed in $\mathrm{N}$-doped $\mathrm{NiO}$, which indicates the existence of nitrogen atoms in $\mathrm{N}$-doped $\mathrm{NiO}$ (Figure 5a). The high-resolution $\mathrm{N}$ 1s peak of $\mathrm{N}$-doped $\mathrm{NiO}$ was deconvoluted into two peaks corresponding to pyridinic and pyrrolic nitrogen components ( 398.5 and $400.1 \mathrm{eV}$, respectively) $[32,33]$. The presence of these nitrogen species confirms $\mathrm{N}$-doping on the surface of $\mathrm{NiO}$ NSs.
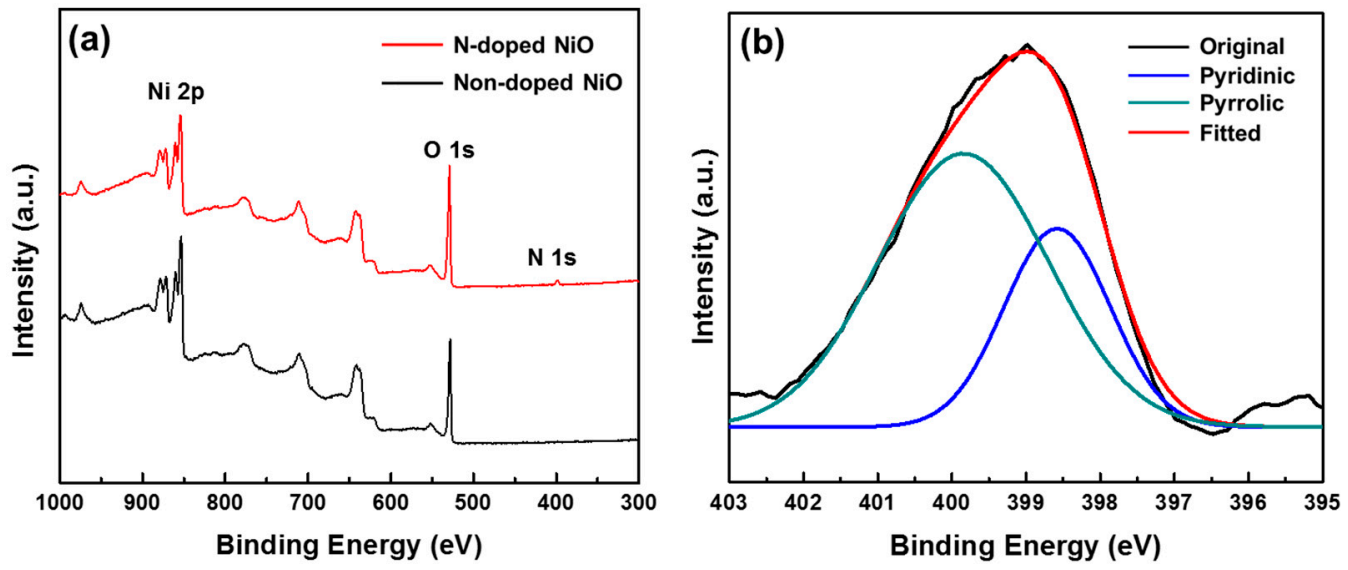

Figure 5. XPS spectra of N-doped and non-doped NiO NSs: (a) wide scan spectra and (b) N 1s spectra of $\mathrm{N}$-doped $\mathrm{NiO}$ with deconvoluted peaks.

\section{4. $\mathrm{NO}_{2}$ Sensing Performance of the $\mathrm{N}$-Doped $\mathrm{NiO}$ NSs Nanostructure}

In order to elucidate the $\mathrm{NO}_{2}$ sensing performance of the synthesized $\mathrm{NiO}$ nanostructures, gas sensing tests were performed at $200{ }^{\circ} \mathrm{C}$ by exposing to various concentrations of $\mathrm{NO}_{2}$, from 1 to $8 \mathrm{ppm}$. Here, the exposing time was $125 \mathrm{~s}$. $\mathrm{NO}_{2}$ was injected into the measurement chamber $\left(200{ }^{\circ} \mathrm{C}\right.$ ) with $\mathrm{N}_{2}$. For a quantitative examination, the responsivity $(R S)$ and sensitivity $(k)$ were investigated with respect to the gas concentration, as defined in Equations (2) and (3):

$$
\begin{gathered}
R S(\%)=\frac{R_{\mathrm{atm}}-R_{\mathrm{G}}}{R_{\mathrm{atm}}} \times 100 \\
k\left(\mathrm{ppm}^{-1}\right)=\frac{R S_{\max }}{C_{\mathrm{G}}}
\end{gathered}
$$

where $R_{\mathrm{atm}}$ is the resistance of the sensors measured under air circumstance and $R_{\mathrm{G}}$ is the resistance when $\mathrm{NO}_{2}$ gas is injected with the carrier gas. The value of $k$ was obtained from the slope of the best linear fitting line in the plots of maximum responsivity $\left(R S_{\max }\right)$ versus $\mathrm{NO}_{2}$ concentration $\left(C_{\mathrm{G}}\right)$. Note that $R_{\mathrm{atm}}$ was measured as $13.5 \mathrm{k} \Omega$. Figure 6a shows that $R S$ increased when the sensor was exposed to $\mathrm{NO}_{2}$ because $R_{\mathrm{G}}$ decreases due to the p-type semiconducting characteristic of $\mathrm{NiO}$, where the $\mathrm{Ni}^{2+}$ vacancies contribute to the hole-conduction [34]. After $\mathrm{NO}_{2}$ disposal, $R S$ was reinstated to its initial stage condition, which represents reversible adsorption and desorption of $\mathrm{NO}_{2}$ on the surface of NiO. The N-doped NiO-NS-based sensor exhibited a two-fold higher $R S$ than that of the non-doped device, which can also be confirmed by its two-fold higher $k$ value in Figure $6 \mathrm{~b}$. Thus, there is a linear relationship between responsivity and $\mathrm{NO}_{2}$ concentration in both types of sensors. Hence, the NiO-NS-based device can be used as quantitative high-precision gas sensors to measure $\mathrm{NO}_{2}$ concentrations.

Note that other reducing gases such as $\mathrm{H}_{2} \mathrm{~S}, \mathrm{NH}_{3}$, and $\mathrm{H}_{2}$ are also applicable to $\mathrm{N}$-doped $\mathrm{NiO}$ NS gas sensors. Because the sensing behaviors of these gases show negative responsivities with increasing values of $R_{\mathrm{G}}$ [24], selective sensing with the reducing gases and $\mathrm{NO}_{2}$ is possible when the NiO-NS-based gas sensors. However, the absolute values of responsivities for such reducing 
gases were still low (less than 50\%). Therefore, it is further required to develop an innovative n-type semiconducting material, which is highly sensitive toward the reducing gases.
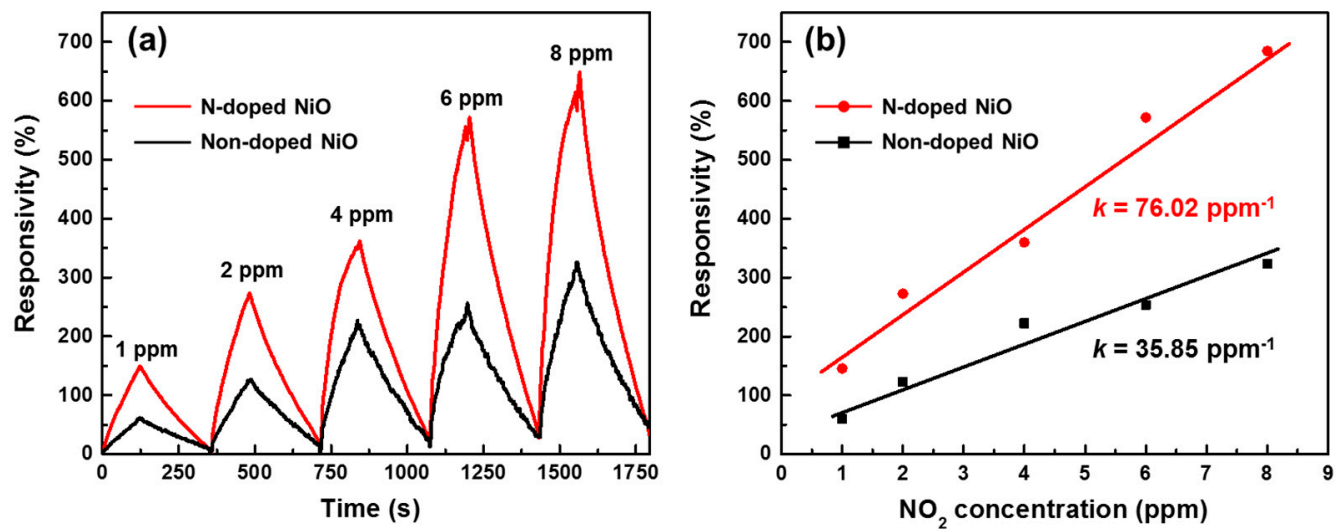

Figure 6. $\mathrm{NO}_{2}$ sensing performance of $\mathrm{N}$-doped and non-doped NiO NSs: (a) responsivity to various gas concentrations and (b) sensitivity plots.

Even though $\mathrm{NO}$ can be considered for use with this gas sensor, direct use is limited because NO reacts well with $\mathrm{O}_{2}$ and produces $\mathrm{NO}_{2}$ easily under a working temperature of $200{ }^{\circ} \mathrm{C}$. In this case, we kept the working temperature at $200{ }^{\circ} \mathrm{C}$ when degassing $\mathrm{NO}_{2}$ after sensing in order to remove residual and adsorbed $\mathrm{NO}_{2}$. Even though the measurement was performed by co-injecting $\mathrm{N}_{2}$ gas, the circumstances under vacuum were not ideal. Therefore, $\mathrm{NO}$ can be reacted with residual $\mathrm{O}_{2}$ at this high working temperature, and the precise amount of $\mathrm{NO}_{2}$ then becomes hard to control.

\subsection{N-Doping Effect on the NiO NSs}

The enhanced $\mathrm{NO}_{2}$ sensing performance of the $\mathrm{N}$-doped $\mathrm{NiO}$ device is because of the increase in p-type conductivity ( $\mathrm{p}^{+}$-type) and the decrease in material resistance by nitrogen doping. Generally, in non-doped $\mathrm{NiO}$, electrical conduction occurs via the hole hopping of $\mathrm{Ni}^{2+}$ vacancies, where each vacancy contributes two holes for conduction associated with a p-type semiconducting characteristic. Moreover, oxygen vacancies act as shallow donors, which are responsible for n-type conductivity. Therefore, the $\mathrm{NO}_{2}$ molecules adsorbed to the $\mathrm{NiO} N S$ surfaces $\left(\mathrm{NO}_{2}(\mathrm{ads})\right)$ accept electrons from the $\mathrm{NiO}$ surface, and this results in the generation of holes $\left(\mathrm{h}^{+}\right)$as per Equation (4):

$$
\begin{gathered}
\mathrm{NO}_{2}(\text { gas }) \rightarrow \mathrm{NO}_{2} \text { (ads) } \\
\mathrm{NO}_{2} \text { (ads) } \rightarrow \mathrm{NO}_{2}^{-}(\text {ads })+h^{+} .
\end{gathered}
$$

When $\mathrm{NO}_{2}$ is adsorbed on the $\mathrm{N}$-doped $\mathrm{NiO}$ surface, holes are generated on the surface by an electron transfer mechanism to the $\mathrm{NO}_{2}$ molecules. Then, the holes on the $\mathrm{N}$-doped $\mathrm{NiO}$ surfaces are transferred to the non-doped $\mathrm{NiO}$ surface (p-type). This hole-transfer at the $\mathrm{p}^{+}-\mathrm{p}$ heterojunction leads to a decrease in resistance of the $\mathrm{NiO}$ backbone, which carries charges between the two electrodes $[35,36]$. Without such heterojunctions, the generated holes are likely to accumulate on the $\mathrm{NiO}$ surface, causing relatively low responsivity owing to the suppression of further adsorption of $\mathrm{NO}_{2}$ molecules. Therefore, the $\mathrm{p}^{+}-\mathrm{p}$ heterojunctions can relieve the amassed holes and can promote the continuous adsorption of $\mathrm{NO}_{2}$, which results in the high responsivity and sensitivity of the sensors. Therefore, the synergetic effect of the p-type semiconducting property of $\mathrm{NiO}$ and the p-type doping of $\mathrm{N}$ increased the performance of the $\mathrm{NO}_{2}$ sensing. 


\subsection{Repetitive and Saturate Responses of the $\mathrm{N}$-Doped $\mathrm{NiO}-\mathrm{NSs}-\mathrm{Based} \mathrm{NO}_{2}$ Sensor}

Furthermore, in order to examine the stability of the $\mathrm{N}$-doped $\mathrm{NiO}$-nased gas sensor, a repetitive $\mathrm{NO}_{2}$ gas sensing test was performed at a specific $\mathrm{NO}_{2}$ gas concentration of $4 \mathrm{ppm}$. The $\mathrm{NO}_{2}$ gas flow was controlled by sequentially turning on (125 s) and turning off ( $250 \mathrm{~s}$ ) and the test was done at $200{ }^{\circ} \mathrm{C}$. As shown in Figure $7 \mathrm{a}$, the synthesized gas sensor exhibited stable reversibility of the gas sensing characteristics under repetitive $\mathrm{NO}_{2}$ exposure conditions, supporting its potential application in $\mathrm{NO}_{2}$ sensors, where cycle-to-cycle variation can be successfully removed. For every cycle, the N-doped $\mathrm{NiO}$-based sensor showed highly amplified responsivity (resistance change) upon $\mathrm{NO}_{2}$ exposure and fully recovered signals in the absence of $\mathrm{NO}_{2}$ with good repetitive switching behaviors. With high sensitivity, highly stable, and repetitive gas sensing performance was observed, which suggests that the presented $\mathrm{N}$-doped $\mathrm{NiO}$ nanostructure-based device has great potential for applications in quantitatively reliable sensors to precisely measure $\mathrm{NO}_{2}$ gas.

Additionally, the $\mathrm{N}$-doped $\mathrm{NiO}$-based sensor showed stable saturate responses for all different concentrations of $\mathrm{NO}_{2}$, as shown in Figure $7 \mathrm{~b}$. After certain injection times, the values of responsivities exhibited steady-state behaviors, which confirms that the developed sensor can give reproducible responses for detecting $\mathrm{NO}_{2}$. For the saturate response, the value of $k_{\text {sat }}$ (Equation (3)) was calculated as $90.13 \mathrm{ppm}^{-1}$ by linear-fitting (root mean square $=0.96$ ). This result shows that N-doped NiO-NS-based gas sensors are highly sensitive toward $\mathrm{NO}_{2}$ gas. Note that previous work using the non-doped $\mathrm{NiO}$ NS on a graphene substrate showed $k=32.4 \mathrm{ppm}^{-1}$. Because the measurement circumstance was kept at a working temperature of $200{ }^{\circ} \mathrm{C}$, even after the gas sensing by $\mathrm{NO}_{2}$ injection, all residual and adsorbed gases could be fully removed from the NiO NSs. Therefore, the device can exhibit stable responses for long-term cycle. It is noted that the $\mathrm{N}$-doped $\mathrm{NiO}$-based gas sensor showed negligible change on repetitive and saturate responses after one month.
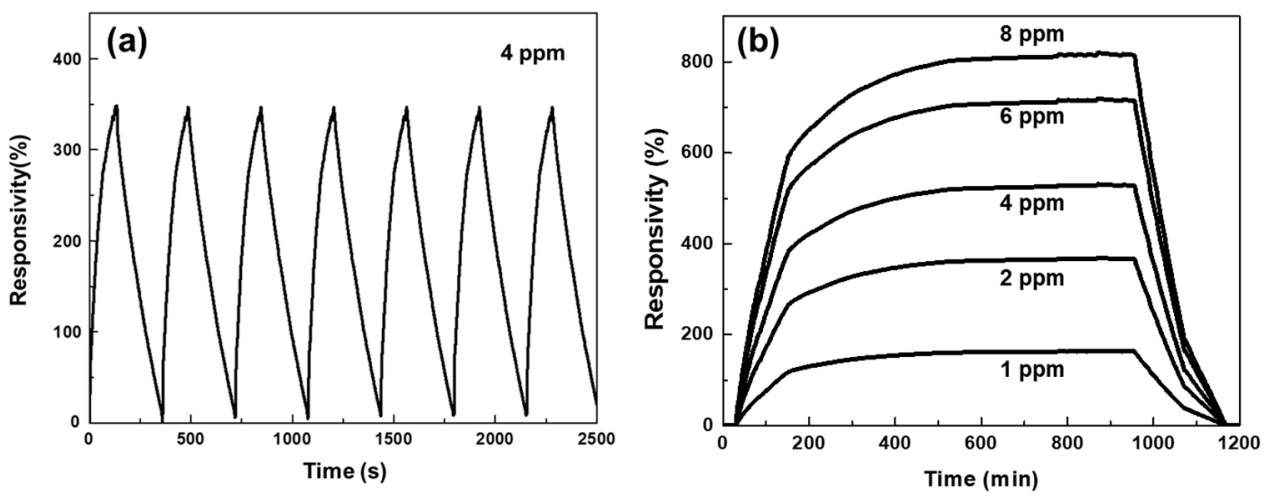

Figure 7. (a) Repetitive and (b) saturate responses of the N-doped $\mathrm{NiO}-\mathrm{NS}$-based $\mathrm{NO}_{2}$ sensors.

\section{Conclusions}

$\mathrm{NiO}$ has been widely used in chemical sensing applications, because it has an excellent p-type semiconducting property and high chemical stability. Here, in order to develop highly sensitive and stable $\mathrm{NO}_{2}$ sensors, we successfully fabricated three-dimensional porous N-doped NiO NSs by a simple and effective hydrothermal technique. N-doping of this novel NiO NS led to significantly enhanced $\mathrm{NO}_{2}$ sensing performance with a two-fold higher responsivity and sensitivity compared to non-doped $\mathrm{NiO}$ NS nanostructure. This was achieved by constructing $\mathrm{p}^{+}-\mathrm{p}$ heterojunctions at the $\mathrm{N}$-doped $\mathrm{NiO}$ sites. The novel $\mathrm{N}$-doped $\mathrm{NiO}$ nanostructure-based device exhibited high sensitivity and stability with good repetitive gas sensing performance. Hence, it is a candidate of choice for quantitatively reliable high-precision gas sensors for the measurement of $\mathrm{NO}_{2}$ gas.

Acknowledgments: This work was supported by the National Research Foundation (NRF) of Korea, a grant funded by the Ministry of Science, ICT and Future Planning (2015R1A2A2A04003160 and 2016M3A7B4021149). 
Author Contributions: Wonoh Lee and Seung Hyun Hur designed the research project. Van Hoang Luan, Huynh Ngoc Tien, and Seung Hyun Hur conceived and designed the experiments; Van Hoang Luan and Huynh Ngoc Tien performed the experiments and analyzed the data; Van Hoang Luan, Jong Hun Han, and Wonoh Lee wrote the paper; all authors discussed and commented on the manuscript.

Conflicts of Interest: The authors declare no conflict of interest.

\section{References}

1. Hjiri, M.; El Mir, L.; Leonardi, S.G.; Donato, N.; Neri, G. CO and $\mathrm{NO}_{2}$ selective monitoring by ZnO-based sensors. Nanomaterials 2013, 3, 357-369. [CrossRef] [PubMed]

2. Duvall, R.M.; Long, R.W.; Beaver, M.R.; Kronmiller, K.G.; Wheeler, M.L.; Szykman, J.J. Performance evaluation and community application of low-cost sensors for ozone and nitrogen dioxide. Sensors 2016, 16, 1698. [CrossRef] [PubMed]

3. Zhang, S.; Hang, N.T.; Zhang, Z.; Yue, H.; Yang, W. Preparation of g- $\mathrm{C}_{3} \mathrm{~N}_{4}$ /graphene composite for detecting $\mathrm{NO}_{2}$ at room temperature. Nanomaterials 2017, 7, 12. [CrossRef] [PubMed]

4. Capone, S.; Rella, R.; Siciliano, P.; Vasanelli, L. A comparison between $\mathrm{V}_{2} \mathrm{O}_{5}$ and $\mathrm{WO}_{3}$ thin films as sensitive elements for NO detection. Thin Solid Films 1999, 350, 264-268. [CrossRef]

5. Diéguez, A.; Romano-Rodríguez, A.; Alay, J.L.; Morante, J.R.; Bârsan, N. Parameter optimisation in $\mathrm{SnO}_{2}$ gas sensors for $\mathrm{NO}_{2}$ detection with low cross-sensitivity to $\mathrm{CO}$ : Sol-gel preparation, film preparation, powder calcination, doping and grinding. Sens. Actuators B Chem. 2000, 65, 166-168.

6. Cheng, J.P.; Wang, J.; Li, Q.Q.; Liu, H.G.; Li, Y. A review of recent developments in tin dioxide composites for gas sensing application. J. Ind. Eng. Chem. 2016, 44, 1-22. [CrossRef]

7. Luan, V.H.; Chung, J.S.; Hur, S.H. Preparation of a reduced graphene oxide hydrogel by Ni ions and its use in a supercapacitor electrode. RSC Adv. 2015, 5, 22753-22758. [CrossRef]

8. Xia, X.H.; Tu, J.P.; Zhang, J.; Wang, X.L.; Zhang, W.K.; Huang, H. Electrochromic properties of porous NiO thin films prepared by a chemical bath deposition. Sol. Energy Mater. Sol. Cells 2008, 92, 628-633. [CrossRef]

9. Varghese, B.; Reddy, M.V.; Yanwu, Z.; Lit, C.S.; Hoong, T.C.; Subba Rao, G.V.; Chowdari, B.V.R.; Wee, A.T.S.; Lim, C.T.; Sow, C.H. Fabrication of $\mathrm{NiO}$ nanowall electrodes for high performance lithium ion battery. Chem. Mater. 2008, 20, 3360-3367. [CrossRef]

10. Garcia-Miquel, J.L.; Zhang, Q.; Allen, S.J.; Rougier, A.; Blyr, A.; Davies, H.O.; Jones, A.C. Nickel oxide sol-gel films from nickel diacetate for electrochromic applications. Thin Solid Films 2003, 424, 165-170. [CrossRef]

11. Kuang, D.B.; Lei, B.X.; Pan, Y.P.; Yu, X.Y.; Su, C.Y. Fabrication of novel hierarchical $\beta-\mathrm{Ni}(\mathrm{OH})_{2}$ and $\mathrm{NiO}$ microspheres via an easy hydrothermal process. J. Phys. Chem. C 2009, 113, 5508-5513. [CrossRef]

12. Vučinić-Vasić, M.; Antic, B.; Kremenović, A.; Nikolic, A.S.; Stoiljkovic, M.; Bibic, N.; Spasojevic, V.; Colomban, $\mathrm{P}$. Zn, $\mathrm{Ni}$ ferrite/ $\mathrm{NiO}$ nanocomposite powder obtained from acetylacetonato complexes. Nanotechnology 2006, 17, 4877-4884.

13. Kwak, B.S.; Choi, B.H.; Ji, M.J.; Park, S.M.; Kang, M. Synthesis of spherical NiO nanoparticles using a solvothermal treatment with acetone solvent. J. Ind. Eng. Chem. 2012, 18, 11-15. [CrossRef]

14. Meng, T.; Xu, Q.Q.; Li, Y.T.; Chang, J.L.; Ren, T.Z.; Yuan, Z.Y. Nickle nanoparticles highly dispersed on reduced graphene oxide for ammonia decomposition to hydrogen. J. Ind. Eng. Chem. 2015, 32, 373-379. [CrossRef]

15. Minegishi, K.; Koiwai, Y.; Kikuchi, Y.; Yano, K.; Kasuga, M.; Shimizu, A. Growth of p-type zinc oxide films by chemical vapor deposition. Jpn. J. Appl. Phys. 1997, 36, L1453-L1455. [CrossRef]

16. Joseph, M.; Tabata, H.; Kawai, T. p-Type electrical conduction in $\mathrm{ZnO}$ thin films by Ga and $\mathrm{N}$ codoping. Jpn. J. Appl. Phys. 1999, 38, L1205-L1207. [CrossRef]

17. Look, D.C.; Reynolds, D.; Litton, C.; Jones, R.; Eason, D.; Cantwell, G. Characterization of homoepitaxial p-type $\mathrm{ZnO}$ grown by molecular beam epitaxy. Appl. Phys. Lett. 2002, 81, 1830-1832. [CrossRef]

18. Liu, G.; Li, F.; Wang, D.W.; Tang, D.M.; Liu, C.; Ma, X.; Lu, G.Q.; Cheng, H.M. Electron field emission of a nitrogen-doped $\mathrm{TiO}_{2}$ nanotube array. Nanotechnology 2008, 19, 025606-025611. [CrossRef] [PubMed]

19. Liu, J.; Dong, L.; Guo, W.; Liang, T.; Lai, W. First principles study of nitrogen doping at the anatase $\mathrm{TiO}_{2}$ (101) surface. J. Phys. Chem. C 2013, 117, 13037-13044. [CrossRef]

20. Abbasi, A.; Sardroodi, J.J. N-doped $\mathrm{TiO}_{2}$ anatase nanoparticles as a highly sensitive gas sensor for $\mathrm{NO}_{2}$ detection: Insights from DFT computations. Environ. Sci. Nano 2016, 3, 1153-1164. [CrossRef] 
21. Livraghi, S.; Paganini, M.C.; Giamello, E.; Selloni, A.; Di Valentin, C.; Pacchioni, G. Origin of photoactivity of nitrogen-doped titanium dioxide under visible light. J. Am. Chem. Soc. 2006, 128, 15666-15671. [CrossRef] [PubMed]

22. Asahi, R.; Morikawa, T.; Ohwaki, T.; Aoki, K.; Taga, Y. Visible-light photocatalysis in nitrogen-doped titanium oxides. Science 2001, 293, 269-271. [CrossRef] [PubMed]

23. Xia, Q.X.; Hui, K.S.; Hui, K.N.; Hwang, D.H.; Lee, S.K.; Zhou, W.; Cho, Y.R.; Kwon, S.H.; Wang, Q.M.; Son, Y.G. A facile synthesis method of hierarchically porous NiO nanosheets. Mater. Lett. 2012, 69, 69-71. [CrossRef]

24. Hoa, L.T.; Tien, H.N.; Luan, V.H.; Chung, J.S.; Hur, S.H. Fabrication of a novel 2D-graphene/2D-NiO nanosheet-based hybrid nanostructure and its use in highly sensitive $\mathrm{NO}_{2}$ sensors. Sens. Actuators $B$ Chem. 2013, 185, 701-705. [CrossRef]

25. Zhang, G.; Yu, L.; Hoster, H.E.; Lou, X.W. Synthesis of one-dimensional hierarchical NiO hollow nanostructures with enhanced supercapacitive performance. Nanoscale 2013, 5, 877-881. [CrossRef] [PubMed]

26. Irwin, M.D.; Servaites, J.D.; Buchholz, D.B.; Leever, B.J.; Liu, J.; Emery, J.D.; Zhang, M.; Song, J.J.; Durstock, M.F.; Freeman, A.J.; et al. Structural and electrical functionality of NiO interfacial films in bulk heterojunction organic solar cells. Chem. Mater. 2011, 23, 2218-2226. [CrossRef]

27. Atay, F.; Bilgin, V.; Akyuz, I.; Kose, S. The effect of in doping on some physical properties of CdS films. Mater. Sci. Semicond. Process. 2003, 6, 197-203. [CrossRef]

28. Haranath, D.; Sahai, S.; Joshi, A.G.; Gupta, B.K.; Shanker, V. Investigation of confinement effects in ZnO quantum dots. Nanotechnology 2009, 20, 425701-425707. [CrossRef] [PubMed]

29. Zhu, W.; Lu, C.H.; Chang, F.C.; Kuo, S.W. Supramolecular ionic strength-modulating microstructures and properties of nacre-like biomimetic nanocomposites containing high loading clay. RSC Adv. 2012, 2, 6295-6305. [CrossRef]

30. Chen, H.L.; Lu, Y.M.; Hwang, W.S. Effect of film thickness on structural and electrical properties of sputter-deposited nickel oxide films. Mater. Trans. 2005, 46, 872-879. [CrossRef]

31. Biju, V.; Khadar, M.A. Electronic structure of nanostructured nickel oxide using Ni 2p XPS analysis. J. Nanopart. Res. 2002, 4, 247-253. [CrossRef]

32. Biesinger, M.C.; Payne, B.P.; Lau, L.W.M.; Gerson, A.; St Smart, R.C. X-ray photoelectron spectroscopic chemical state quantification of mixed nickel metal, oxide and hydroxide systems. Surf. Interface Anal. 2009, 41, 324-332. [CrossRef]

33. Zhuang, Z.; Giles, S.A.; Zheng, J.; Jenness, G.R.; Caratzoulas, S.; Vlachos, D.G.; Yan, Y. Nickel supported on nitrogen-doped carbon nanotubes as hydrogen oxidation reaction catalyst in alkaline electrolyte. Nat. Commun. 2016, 7, 10141. [CrossRef] [PubMed]

34. Delegan, N.; Daghrir, R.; Drogui, P.; El Khakani, M.A. Bandgap tailoring of in-situ nitrogen-doped $\mathrm{TiO}_{2}$ sputtered films intended for electrophotocatalytic applications under solar light. J. Appl. Phys. 2014, 116, 153510-153518. [CrossRef]

35. Biju, V.; Khadar, M. Dielectric properties of nanostructured nickel oxide. J. Mater. Sci. 2003, 38, 4055-4063. [CrossRef]

36. Vasu, K.; Sreedhara, M.B.; Ghatak, J.; Rao, C.N.R. Atomic layer deposition of p-type epitaxial thin films of undoped and $\mathrm{N}$-doped anatase $\mathrm{TiO}_{2}$. ACS Appl. Mater. Interfaces 2016, 8, 7897-7901. [CrossRef] [PubMed]

(C) 2017 by the authors. Licensee MDPI, Basel, Switzerland. This article is an open access article distributed under the terms and conditions of the Creative Commons Attribution (CC BY) license (http://creativecommons.org/licenses/by/4.0/). 